\title{
Belowground induction by Delia radicum or phytohormones affect aboveground herbivore communities on field-grown broccoli
}

\author{
S. P. Pierre ${ }^{1}$, S. Dugravot ${ }^{1,2}$, M. R. Hervé ${ }^{1,2}$, H. M. Hassan ${ }^{3}$, N. M. van Dam ${ }^{4}$ and A. M. Cortesero ${ }^{1,2 *}$ \\ 1 Institute of Genetic, Environment and Plant Protection (Mixed Research Unit 1349), Rennes 1 University, Rennes, France \\ 2 European University of Brittany, Brittany, France \\ ${ }^{3}$ Economic Entomology, Kafrelsheikh University, Kafr El-Sheikh, Egypt \\ ${ }^{4}$ Department of Ecogenomics, Institute for Water and Wetland Research, Radboud University Nijmegen, Nijmegen, Netherlands
}

Edited by:

Ana Pineda, Wageningen University, Netherlands

\section{Reviewed by:}

Cesar Rodriguez-Saona, Rutgers

University, USA

Christelle A. M. Robert, Max Planck

Institute, Germany

\section{*Correspondence:}

A. M. Cortesero, Institute of

Genetic, Environment and Plant

Protection, Rennes 1 University,

263 Avenue du Général Leclerc,

F-35000 Rennes, France

e-mail: anne-marie.cortesero@

univ-rennes 1.fr
Induced plant defence in response to phytophagous insects is a well described phenomenon. However, so far little is known about the effect of induced plant responses on subsequently colonizing herbivores in the field. Broccoli plants were induced in the belowground compartment using (i) infestation by the root-herbivore Delia radicum, (ii) root application of jasmonic acid (JA) or (iii) root application of salicylic acid (SA). The abundance of $D$. radicum and six aboveground herbivores displaying contrasting levels of host specialization were surveyed for 5 weeks. Our study showed that the response of herbivores was found to differ from one another, depending on the herbivore species, its degree of specialization and the root treatment. The abundance of the root herbivore $D$. radicum and particularly the number of emerging adults was decreased by both phytohormone treatments, while the number of $D$. radicum eggs was increased on conspecific infested plants. The root infestation exhibited moderate effects on the aboveground community. The abundance of the aphid Brevicoryne brassicae was strongly increased on $D$. radicum infested plants, but the other species were not impacted. Root hormone applications exhibited a strong effect on the abundance of specialist foliar herbivores. A higher number of $B$. brassicae and Pieris brassicae and a lower number of Plutella xylostella were found on JA treated plants. On SA treated plants we observed a decrease of the abundance of B. brassicae, Pi. rapae, and P. xylostella. Surprisingly, generalist species, Mamestra brassicae and Myzus persicae were not affected by root induction treatments. Finally, root treatments had no significant effect on either glucosinolate (GLS) profiles of the heads or on plant quality parameters. These results are discussed from the perspective of below- aboveground interactions and adaptations of phytophagous insects to induced plant responses according to their trophic specialization level.

Keywords: plant-mediated above-belowground interactions, induced plant defence, Brassica spp, root herbivory, phytohormones

\section{INTRODUCTION}

Induced plant resistance against herbivores is a widespread phenomenon, reported for over one hundred plant species (Karban and Baldwin, 1997). Induced responses include physical and chemical alterations such as modification in leaf toughness, trichome density, as well as changes in the concentration of allelochemicals and nutritional compounds (Karban and Baldwin, 1997). In the field, such plant responses induced early in the season may affect subsequently colonizing herbivores (Shiojiri et al., 2002; Viswanathan et al., 2005; Poelman et al., 2008, 2010). The effect of induced plant responses may have contrasting effects on host-plant acceptance by herbivores belonging to different feeding guilds or having different levels of host specializations (Inbar et al., 1999; Agrawal, 2000; Denno et al., 2000). In particular, it has been found that generalist herbivores tend to avoid induced plants while specialists prefer to colonize such plants (Martinsen et al., 1998; Kaplan and Denno, 2007; Long et al., 2007; Poelman et al., 2008, 2010). This dissimilarity could result in important modifications of herbivore communities associated with individual plants depending on their induction status (van Zandt and Agrawal, 2004; Poelman et al., 2010). So far, studies on the influence of induced responses on herbivore community structure have been focused on the aboveground compartment. However, there is a growing awareness that plants and insects are part of complex and connected multitrophic aboveground and belowground communities (van Dam and Heil, 2011). Although aboveground and belowground responses are sometimes independent (Bezemer et al., 2003, 2004), they may also interact with each other. Indeed, several studies reported that root herbivoryor hormone applications as a substitute for root feeding-not 
only causes a local (root) but also a systemic (foliar) increase in levels of defence compounds [reviewed by Bezemer and van Dam (2005); Erb et al. (2008); van Dam and Heil (2011)]. Jasmonic acid (JA) is known to be a central signaling compound in plant defence induction against chewing insects (Howe and Jander, 2008) that is upregulated in the roots after belowground attack (Erb et al., 2009). Nevertheless its relative importance as a defence signal belowground is still unclear. Salicylic acid (SA) is known to be involved in responses to sap-sucking insects and pathogens, and can act as JA antagonist (Becker and Spoel, 2006). Topical applications of both hormones have been used successfully to mimic herbivore and pathogen induced response in plants (e.g., Moore et al., 2003). Although root and shoot chewers may elicit similar induction pathways, root induction can trigger different responses in the leaves when compared to leaf attack (Masters et al., 1993; van Dam et al., 2004).

Root-induced changes in plant defence can have major impacts on aboveground organisms feeding on the plant. In some cases, such plant induced responses result in lower performance of leaf herbivores (Bezemer et al., 2003; Soler et al., 2005; van Dam et al., 2005). In other cases, root herbivores also induce a stress response in the host plant similar to drought stress, leading to the reallocation of photoassimilates in shoots and, consequently, affecting positively or negatively the performance of foliar feeders (Masters et al., 1993; Huberty and Denno, 2004; Erb et al., 2011a). Therefore it is hard to predict the effects of root induced response on foliar herbivores without experimental assessments. A few authors have investigated whether aboveground induced plant responses to herbivory or phytohormone applications are costly by quantifying plant growth, survival and reproduction (e.g., Thaler, 1999; Agrawal, 2000; Redman et al., 2001; van Dam and Baldwin, 2001). However, to our knowledge thus far it has not been examined if root induction by insect herbivory or phytohormone applications affects the herbivore community associated with a crop and if such induction has any influence on the yield and nutritional quality of the harvested products.

Delia radicum L., the cabbage root fly, is a major pest of brassicaceous crops such as broccoli, Brussels sprouts, cabbages and kales. Females aggregatively lay their eggs near plant stems and the larvae crawl down to feed on the roots before pupating in the soil surrounding the roots. Plant mortality caused by larval damage may lead to significant reductions in yield, flowering, and seed production as well as in leaf, stem and root biomass (de Jong and Städler, 1999). This root herbivore is also a well-studied model system for plant-mediated above-belowground interactions. Experiments using cultivated and wild Brassica species showed that root feeding by $D$. radicum and its close relative $D$. floralis, induce notable changes in the levels of primary and secondary non-volatile compounds in the plant (Birch et al., 1992; Hopkins et al., 1998, 1999; Soler et al., 2005; van Dam et al., 2005; van Dam and Raaijmakers, 2006; Pierre et al., 2012) as well as changes in its volatile blend (Neveu et al., 2002; Soler et al., 2007; Pierre et al., 2011). In particular, D. radicum feeding on roots was shown to induce both a local (in roots) and a systemic (in shoots) increase of indole and aliphatic glucosinolates (GLS) levels in wild Brassica species (van Dam and Raaijmakers, 2006). This systemic induced response to $D$. radicum feeding could contribute at least partly to reduced performance of the leaf feeder specialist Pieris brassicae on feral B. nigra plants (Soler et al., 2005).

Here, we present a field experiment on broccoli (Brassica olearacea subps. italica) in which we specifically address the following questions: (i) does root herbivory, JA or SA root application affect plant colonization by subsequent herbivorous insects attacking the leaves or the roots of this plant? (ii) do herbivores of different feeding guilds and levels of host specialization differ in their response to root-induced plants? (iii) do the root induction treatments affect yield and quality of the crop?

\section{MATERIALS AND METHODS PLANTS}

Cultivated broccoli plants, Brassica oleracea subsp. italica (var. Monaco) were used for the experiment. Seeds were sown individually in peat soil cylinders and grown during 6 weeks in a plastic tunnel (Technosem, Cleder, Brittany, France). The experimental site was located in the "Domaine experimental de la Motte" (INRA center, Le Rheu, Brittany, France). Before plantation, the soil was fertilized ( $100 \mathrm{~N}$ units) and treated with an herbicide (Butisan ${ }^{\circledR} \mathrm{S}$ at a dose of $2 \mathrm{~L} / \mathrm{Ha}$ ). Four days later (28th of April, 2009), the broccoli seedlings were transplanted into the soil at a density of 2.7 plants $/ \mathrm{m}^{2}$. We used an anti-insect netting (Multiclima ${ }^{\circledR}$, "Genetic et Distribution," France) to prevent the plants from natural infestation before the beginning of the experimental survey. This net is transparent and made of U.V. treated high-density polyethylene (HDPE, $38 \mathrm{~g} / \mathrm{m}^{2}, 16 \%$ shade, with an average of $2^{\circ} \mathrm{C}$ difference from the ambient temperature). It is successfully used in various vegetable crops in Brittany as an alternative for pesticide treatments (Loïc Gueguen, pers. communication). Here the net was removed at a date (11th of June, 2009) corresponding to the beginning of the second $D$. radicum egg laying period and to the increased presence of various common Brassica pests such as Plutella xylostella, Pieris brassicae, and Brevicoryne brassicae (Bulletin de Santé du Végétal, DRAF Brittany website). At that time, the broccoli plants had 12-13 fully expanded leaves.

\section{INSECTS}

For the plant infestation, we used $D$. radicum larvae originating from our rearing. The populations were originally established in the laboratory from flies collected in the field at St. Méloir des Ondes (Brittany, France) during the summer of 1994. The brood was reared as described in Neveu et al. (1996) and supplemented yearly with new field-captured individuals coming from the same area.

\section{FIELD EXPERIMENTAL SET UP}

A randomized complete block design was established at the same time as the anti-insect net was removed from the broccoli crop (11th of June 2009). Three blocks were constituted, each one included five randomized plots corresponding to the five different treatments tested. A plot consisted of 20 plants (five rows of four plants each). The plots were isolated from each other by a row of untreated broccoli plants. Induction treatments were applied $3 \mathrm{~h}$ after net removal. Infestation with $D$. radicum was carried out by placing five larvae (second and third instars) with a brush onto 
the soil surface immediately adjacent to the stem of each plant. This load of infestation was previously shown to trigger an alteration of the chemical profile of the plant (Pierre et al., 2011, 2012). Control plants for this induction treatment were plants that were not infested (C). Root treatments with JA and SA were made using the same procedure and the same phytohormone doses (i.e., $500 \mu \mathrm{g}$ and $25 \mathrm{mg}$ per plant, corresponding to 0.23 and $18 \mathrm{mM}$ respectively) as described by van Dam et al. (2004) and for which induction of GLS was successfully demonstrated under controlled conditions (Pierre et al., 2012). To optimize induction in our field conditions, we repeated the phytohormone treatments two times during the experiment, the 22nd of June and the 6th of July. Control plants for such phytohormone inductions (AC) were treated with an acid solution $(\mathrm{pH}=3.1$ between $\mathrm{pH}$ of JA solution and SA solution) according to the same method as described by van Dam et al. (2004).

\section{EFFECT OF INDUCTION ON HERBIVORE COMMUNITY}

During the season, we surveyed six herbivorous species on the plants (Table 1). Other herbivores that were observed, namely flea beetles, whiteflies and thrips, were excluded from the survey as they could not be accurately counted without damaging the plants.

From June 25th until July 15th, the four central plants of each plot were surveyed weekly by investigating both sides of all their leaves for the presence of herbivorous insects. In addition, egg laying by $D$. radicum was monitored weekly on two plants of each plot from June 18th until July 15th. For this purpose, felt traps were positioned around the stems of the plants, where flies deposit their eggs (Bligaard et al., 1999). These traps are used by farmers as an indicator of pest prevalence. The traps were collected and eggs found inside were counted and removed at each survey. Empty traps were then replaced on the same plants. In addition, at the harvest (described below), we dug out the entire roots and soil in a radius of $15 \mathrm{~cm}$ around the main root and at a depth of $20 \mathrm{~cm}$, for three to six harvested plants per treatment group. The plants chosen were different from the ones used for monitoring D. radicum oviposition. These "root-soil" samples were put in separate plastic bags and brought back to the lab. Each sample was individually potted and covered with a micro-aerated plastic bag to control and survey Delia spp adult emergence. Based on identification of a representative sample of one hundred individuals under a binocular microscope, $D$. radicum individuals were found to be highly predominant, i.e., representing $99 \%$ of total Delia spp individuals, compared to the other species such as D. antiqua and D. platura which can also feed on Brassica plant roots and pupate in the soil. For this reason, all emerged adults were considered as belonging to Delia radicum species.

\section{EFFECTS OF INDUCTION ON HARVEST YIELD AND QUALITY}

The four central broccoli plants that were surveyed for herbivores and six other plants randomly selected from each plot were harvested on June 16th and 17th, which resulted into 10 plants * 3 blocks $=30$ plants per treatment group. The height of each plant was measured before cutting it with clippers at $10-15 \mathrm{~cm}$ over the root-shoot interface. One hour later, each entire plant was weighed (balance Mettler PM 3000) with \pm 0.1 g accuracy. A general quality grade was assigned to each plant that was estimated as an average grade between commercial specifications for head quality (CEE-ONU FFV-48 standards reviewed) and visual aspect of the leaves. The classes were: Class1: leaves and head are green and without any apparent herbivore damage; head is firm, tight and deep green; Class 2: at least $90 \%$ of leaves and head are green and without apparent herbivore damage; at least $90 \%$ of head is firm, tight and deep green; Class 3: any other plant that does not match Classes 1 or 2 .

The heads (cut with clippers to get $16-18 \mathrm{~cm}$ high heads, stem included) were weighed to determine their fresh biomass. Meanwhile, samples from 10 to 16 heads per treatment group were placed in separate paper bags to be stored at $-20^{\circ} \mathrm{C}$ until they were freeze-dried to constant weight. A sub-sample of 90 $110 \mathrm{mg}$ was taken from each dried head sample and put individually in Eppendorf tubes for GLS profile analysis, by following similar procedures as described by van Dam and Raaijmakers (2006).

\section{STATISTICS}

All statistical analyses were carried out with $\mathrm{R}$ software (version 2.14.0; R Core Team, 2011). Effect of treatment (D. radicum infestation or phytohormone application) on herbivore abundance was assessed using a Wald chi square test on a Generalized Linear Mixed Model, with a Poisson distribution (function "glmer" in package "lme4"; Bates et al., 2011). Data considered were the number of individuals/eggs per plant. Since the two control treatments (AC and $\mathrm{C}$ ) were conducted differently, two models were

Table 1 | Herbivore species surveyed on Brassica oleracea subsp. italica (var. Monaco) experimental plots, and their degrees of host specialization.

\begin{tabular}{|c|c|c|c|c|}
\hline Species & Order & Family & Feeding type & Host specificity \\
\hline Delia radicum & Diptera & Anthomyiidae & Root chewer & Specialist \\
\hline Pieris brassicae & Lepidoptera & Pieridae & Leaf chewer & Specialist \\
\hline Pieris rapae & Lepidoptera & Pieridae & Leaf chewer & Specialist \\
\hline Plutella xylostella & Lepidoptera & Yponomeutidae & Leaf chewer & Specialist \\
\hline Mamestra brassicae & Lepidoptera & Noctuidae & Leaf chewer & Generalist \\
\hline Brevicoryne brassicae & Hemiptera & Aphididae & Phloem feeder & Specialist \\
\hline Myzus persicae & Hemiptera & Aphididae & Phloem feeder & Generalist \\
\hline
\end{tabular}


built: one to test for an effect of phytohormone application, a second one to test for an effect of $D$. radicum infestation. In both models, treatment was specified as a fixed factor, date was specified as a random factor and block was specified as a random factor nested into date. The same procedure was used to test for an effect of treatment on abundance of $D$. radicum adults, without the date factor. When needed, pairwise comparisons were computed by using an analysis of contrasts [function "esticon" in package "doBy" (Højsgaard et al., 2011)] with a Benjamini-and-Hochberg correction.

Effect of treatment on plant quality (height, total weight, head weight and visual quality) was assessed by using a Wald chi square test on a Linear Mixed Model (function "lmer" in package "lme4"). Treatment was considered as a fixed factor and block as a random factor. When needed, pairwise comparisons were computed by an analysis of contrasts with a Benjamini-and-Hochberg correction.

Effect of treatment on GLS profile was assessed by using an Analysis Of Variance (ANOVA). Different ANOVAs were conducted to test for an effect on (i) total GLS, (ii)
GLS classes (aliphatic and indole), and (iii) individual GLS content.

\section{RESULTS}

\section{D. radicum ABUNDANCE}

\section{Effect of phytohormone treatment}

Both egg abundance and adult emergence of the specialist root herbivore $D$. radicum were altered by phytohormone treatments (Figure 1). The number of eggs laid by D. radicum $(p<0.0001)$ was decreased on JA-treated plants but not on SA-treated plants $(p=0.25)$. Significantly lower numbers of adults emerged from JA $(p=0.0094)$ and SA treated plants $(p=0.0094)$ than from untreated plants.

\section{Effect of $D$. radicum infestation}

In contrast to the treatments with phytohormones, $D$. radicum infestation was clearly associated with higher numbers of conspecific $D$. radicum eggs ( $p=0.0005$ ) (Figure 2 ). However, the number of adults emerging from these previously infested plants was not different from control plants $(p=0.061)$.
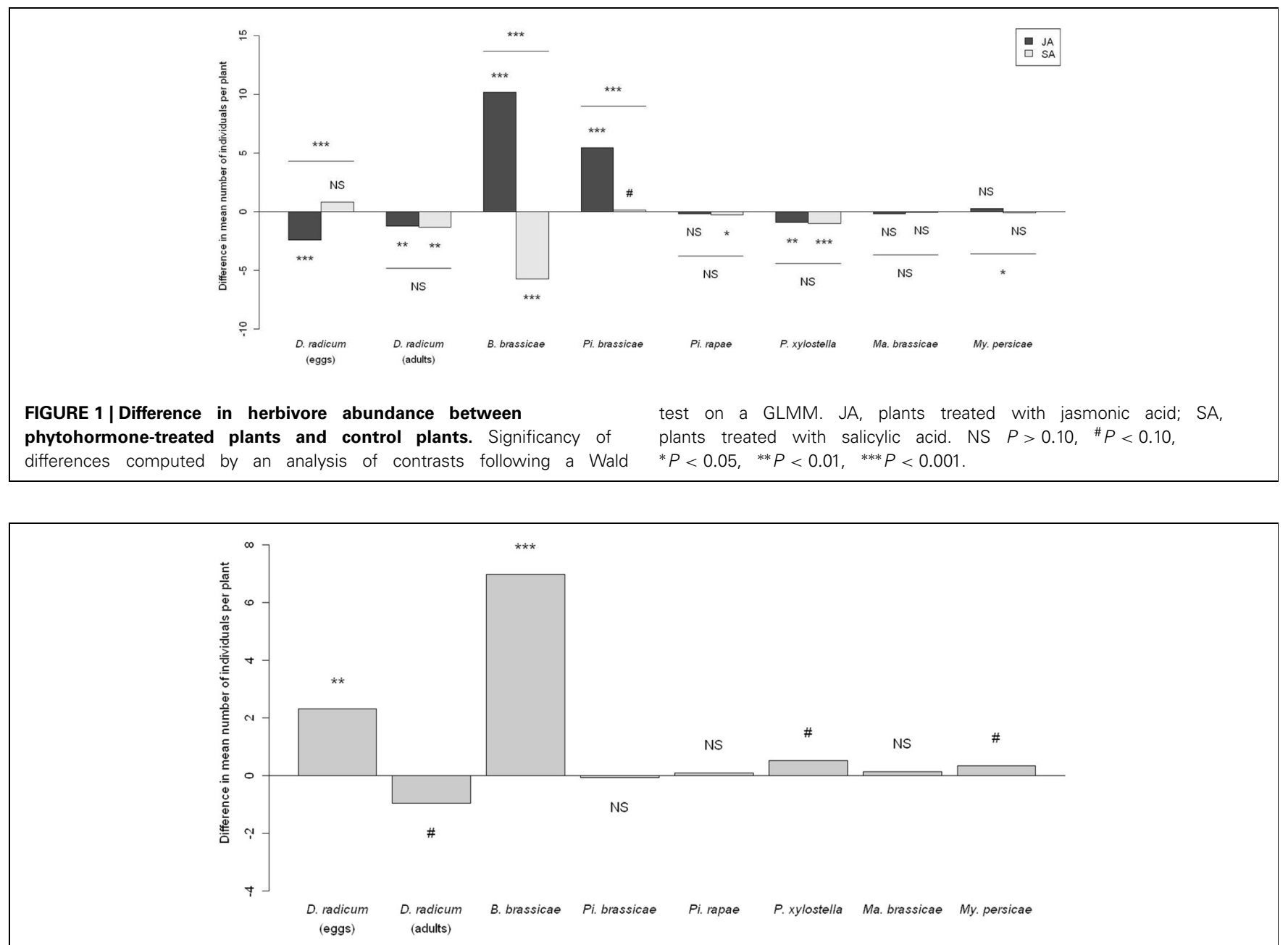

FIGURE $\mathbf{2}$ | Difference in herbivore abundance between $\boldsymbol{D}$. radicum-infested plants and control plants. Significancy of differences computed by a Wald test on a GLMM. NS $P>0.10,{ }^{\#} P<0.10,{ }^{* *} P<0.01,{ }^{* * *} P<0.001$ 


\section{FOLIAR HERBIVORE ABUNDANCE}

\section{Effect of phytohormone treatment}

Herbivore community development was globally affected by phytohormone treatments, however, the magnitude of the effect varied for some species and according to the phytohormone tested (Figure 1).

JA treated plants harbored more specialist $P i$. brassicae larvae $(p<0.0001)$ and showed a higher abundance of the specialist $B$. brassicae $(p<0.0001)$. Conversely, JA application was associated with a lower abundance of the specialist $P$. xylostella $(p=$ $0.001)$. This treatment however, did not affect the abundance of the other specialist Pi. rapae and the two generalists $M y$. persicae and Ma. brassicae.

Conversely to JA, SA treated plants harbored fewer individuals of the specialist $B$. brassicae $(p<0.0001)$ but also fewer Pi. rapae $(p=0.019)$ and $P$. xylostella larvae $(p=0.0058)$. This treatment did not strongly affect the number of $P i$. brassicae larvae $(p=0.0975)$. As for JA, SA applications had no influence on the abundance of the generalists Ma. brassicae and My. persicae.

\section{Effect of $D$. radicum infestation}

Delia radicum induced plants harbored more specialist $B$. brassicae individuals $(p<0.0001)$, more specialist $P$. xylostella larvae although the test was just not significant ( $p=0.0592$, Figure 2) but the abundance of all the other herbivores was not significantly affected by $D$. radicum infestation.

\section{EFFECT OF TREATMENTS ON HARVEST YIELD, QUALITY AND GLS HEAD PROFILES}

JA treated plants had reduced heights compared to control plants $(34.5 \pm 0.9 \mathrm{~cm}$ and $37.7 \pm 0.7 \mathrm{~cm}$, respectively; $d f=85$, $t=2.968, p=0.004)$. By contrast, neither SA application nor $D$. radicum infest ation modified plant height compared to controls $(36.6 \pm 0.7 \mathrm{~cm}, 37.1 \pm 0.7 \mathrm{~cm}$ and $36.7 \pm 0.6 \mathrm{~cm}$, respectively) (Table 2).

Phytohormone treatments did not change plant quality when considering visual aspects of their leaves and heads, whereas $D$. radicum infested plants showed lower quality than control plants (average quality grades were $1.7 \pm 0.1$ and $2.1 \pm 0.1$, respectively; $z=-2.16, p=0.0259)$. Neither induction with phytohormone applications nor $D$. radicum infestation did affect fresh biomass of heads or shoots (Table 2).

The GLS profile of the broccoli heads harvested 35 or 36 days after planting consisted of two aliphatic GLS, i.e., glucoraphanin and glucoiberin, four indole GLS, i.e., glucobrassicin, neoglucobrassicin and two unknown indole GLS (Table 3). The GLS profiles of the heads were not affected by any of the induction treatments.

\section{DISCUSSION}

Herbivore induced plant responses are known to mediate interactions between insect herbivores that are spatially (i.e., either associated to above- or belowground plant compartments) and temporally separated (Englishloeb et al., 1993). However, the

Table 2 | Effect of phytohormone treatments or D. radicum infestation on different parameters of plant quality (Wald tests on GLMMs).

\begin{tabular}{|c|c|c|c|c|c|c|c|c|c|c|c|}
\hline Variable & \multicolumn{6}{|c|}{ Phytohormone treatment } & \multicolumn{5}{|c|}{ D. radicum infestation } \\
\hline Height (cm) & 7.67 & 2 & 0.0246 & $37.70(0.74) \mathrm{A}$ & $34.65(0.95) \mathrm{B}$ & 36.60 (0.69) A,B & 0.19 & 1 & 0.6641 & $36.68(0.63)$ & $37.10(0.73)$ \\
\hline Plant weight (g) & 4.13 & 2 & 0.1268 & $2131.6(62.5)$ & $2082.8(81.3)$ & $1936.6(69.2)$ & 0.57 & 1 & 0.4497 & $2037.23(69.87)$ & $2109.33(66.16)$ \\
\hline Head weight (g) & 2.41 & 2 & 0.2994 & $873.5(48.3)$ & $864.3(57.2)$ & 774.5 (46.0) & 0.35 & 1 & 0.5518 & $826.48(43.71)$ & $863.67(45.33)$ \\
\hline Visual quality & 0.68 & 2 & 0.7130 & $1.97(0.10)$ & $1.87(0.11)$ & $2.00(0.14)$ & 4.96 & 1 & 0.0259 & $2.13(0.12)$ & $1.73(0.14)$ \\
\hline
\end{tabular}

Values presented are means $( \pm S E)$. For phytohormones when the global effect is significant, different letters indicate statistically different means at $P<0.05$. JA, plants treated with jasmonic acid; SA, plants treated with salicylic acid.

Bold value indicates $P<0.05$.

Table 3 | Mean levels of glucosinolates ( $\mu$ moles/g dry mass) ( \pm SE) in heads of harvested broccoli.

\begin{tabular}{|c|c|c|c|c|c|c|c|c|c|c|c|}
\hline Class/compound & \multicolumn{6}{|c|}{ Phytohormone treatment } & \multicolumn{5}{|c|}{ D. radicum infestation } \\
\hline Glucoraphanin & 2.10 & 2 & 0.1372 & $0.33(0.08)$ & $0.28(0.08)$ & $0.60(0.17)$ & 2.24 & 1 & 0.1485 & $0.38(0.10)$ & $0.67(0.19)$ \\
\hline Glucoiberin & 1.27 & 2 & 0.2932 & $0.07(0.01)$ & $0.05(0.01)$ & $0.09(0.03)$ & 3.58 & 1 & 0.0712 & $0.06(0.01)$ & $0.11(0.02)$ \\
\hline Indole & 0.68 & 2 & 0.5110 & $0.87(0.20)$ & $0.76(0.26)$ & $1.14(0.22)$ & 0.55 & 1 & 0.4643 & $0.73(0.15)$ & $0.93(0.24)$ \\
\hline Unknown indole 1 & 1.64 & 2 & 0.2085 & $0.09(0.05)$ & $0.06(0.02)$ & $0.19(0.07)$ & 0.38 & 1 & 0.5440 & $0.10(0.03)$ & $0.07(0.03)$ \\
\hline Unknown indole 2 & 0.14 & 2 & 0.8705 & $0.02(0.00)$ & $0.02(0.01)$ & $0.02(0.00)$ & 0.01 & 1 & 0.9048 & $0.02(0.00)$ & $0.02(0.00)$ \\
\hline Total & 1.25 & 2 & 0.2990 & $1.27(0.28)$ & $1.09(0.34)$ & $1.83(0.38)$ & 1.41 & 1 & 0.2472 & $1.17(0.26)$ & $1.72(0.41)$ \\
\hline
\end{tabular}

JA, plants treated with jasmonic acid; SA, plants treated with salicylic acid. 
aboveground community-wide consequences of belowground induced responses and their impact on plant productivity have been rarely investigated so far. Here, we demonstrated under realistic field conditions that root induction of broccoli plants by $D$. radicum feeding or phytohormones not only affects the colonization by naturally occurring $D$. radicum females but also the community structure of several leaf herbivore species sharing the same host plant. Our study showed that both leaf-chewing and sap-sucking herbivore abundance can be influenced by root induction. However, the response of herbivores belonging to these feeding guilds were found to differ from one another, depending on the herbivore species, its degree of specialization and the root treatment.

\section{EFFECTS OF ROOT INDUCTION TREATMENTS ON D. radicum}

The belowground herbivore, $D$. radicum was affected by all root induction treatments. JA application reduced the number of $D$. radicum eggs, while SA did not. This reduction in egg number could be due to a systemic modification of the chemical cues (volatile or not) produced aboveground (van Dam et al., 2004) and used by D. radicum to select a host plant (Finch and Collier, 2000). As JA treated plants were slightly smaller than control plants, a visual effect cannot be excluded. Both phytohormone treatments decreased the number of emerging adults. These results suggest that both JA and SA application may modify the suitability of the host plant for the development of the cabbage root-fly larvae. It has previously been shown that JA and SA application on Brassica species could induce a local alteration of chemicals such as GLS (Kiddle et al., 1994; van Dam et al., 2004; Pierre et al., 2012) that may affect D. radicum larval performance and therefore reduce the number of emerging adults as it was already observed on JA treated broccoli plants (Pierre et al., 2012). Nevertheless, the lower number of emerging adults found on JA treated plants could result not only from a direct effect on larval performance but also from the reduction in the number of eggs laid that has been observed in this study.

Our study showed that $D$. radicum infestation triggered different effects than phytohormone applications on conspecific colonization. The number of eggs laid was strongly increased on root infested plants as previously shown in lab experiments (Baur et al., 1996). Surprisingly the higher number of eggs found on conspecific infested plants did not result in a higher emergence rate of $D$. radicum. This paradox between herbivore preference and performance might result from differential plant induced response between shoots and roots (van Dam and Raaijmakers, 2006). Lower performance on plants harboring a large egg load may also result from a higher density of conspecific competitors on the root as was previously shown on other root herbivores (Robert et al., 2012). In this case, an induced plant that stimulates oviposition may become less suitable for the development of the progeny. In addition, the increase of the larval density could lead to a possible competition for resources between larvae and therefore decrease their survival rate (Ellner et al., 2001; Robert et al., 2012).

For all the induction treatments, the reduction in number of emerging adults may also be due to attraction of natural enemies such as eggs predators (i.e., carabids or staphylinids) (Coaker and Williams, 1963). Previous studies have shown that JA or SA treated plants could be attractive for herbivores natural enemies (van Poecke and Dicke, 2002; Orre et al., 2010). In addition, D. radicum infested are attractive for the eggs predators Aleochara bipustulata and Aleochara bilineata (Ferry et al., 2007).

Finally, in modifying the relative abundance of leaf herbivores, the root induction treatments could also have an indirect effect on the root feeder performances. For instance, it has been shown that the feeding activity of Brevicoryne brassicae on Arabidopsis thaliana leaves has a negative impact on nematode performances (Kutyniok and Muller, 2012). This emphasizes the fact that sequence of arrival can be an important factor shaping plant mediated interactions between herbivores (Erb et al., 2011b). In this study the root induction treatments may affect the sequence of arrival of several phytophagous species that can consequently impact the colonization processes of other species.

\section{EFFECTS OF ROOT INDUCTION TREATMENTS ON THE ABOVEGROUND COMMUNITY}

The aboveground community was more affected by root hormone applications than by previous $D$. radicum root infestation. Nevertheless the effects of root hormone applications on the aboveground herbivore community were somehow surprising. Indeed they did not follow predictable patterns as could be expected based on the general trends reported in the literature, predicting that generalist herbivores tend to avoid induced plants while specialists prefer to colonize them (Martinsen et al., 1998; Kaplan and Denno, 2007; Long et al., 2007; Poelman et al., 2008, 2010). In our study, the generalist foliar herbivores (My. persicae and Ma. brassicae) were not affected by phytohormone treatments, while the specialists exhibited contrasted effects depending on the herbivore species and the applied hormone. Two specialist foliar herbivores (B. brassicae and Pi. brassicae) were more abundant on JA treated plants whereas the specialist $P$. xylostella displayed the opposite response. Interestingly, the abundance of three specialist species (B. brassicae, Pi. rapae and P. xylostella) was decreased, but never increased, on SA treated plants. The leaf chewer specialist P. xylostella was the only species to respond negatively to both root phytohormone applications, contrasting with experiments performed by Shiojiri et al. (2002); Poelman et al. (2008, 2010), and Mathur et al. (2011) who observed a strong preference of P. xylostella for induced Brassica plants. However, all these studies focused on aboveground herbivore responses to shoot induction while we worked with root induced plants. Our findings support previous studies showing that shoot and root induction may differentially affect leaf chemistry and herbivore growth (e.g., van Dam and Oomen, 2008; Qiu et al., 2009). For example, (van Dam et al., 2004; van Dam and Oomen, 2008), showed that feral B. oleracea plants induced by root treatment with JA displayed higher levels of aliphatic GLS in the leaves, whereas shoot treatment with JA increased indole GLS. Nevertheless, root treatment with SA on B. oleracea induced a local but not systemic increase of GLS (van Dam et al., 2004). In our study we observed no change in the final GLS profiles of broccoli heads. However, short term effects of the induction treatments are possible. Indeed, significant effects were observed in feral B. oleracea plants at 3-7 days after JA application, and 
may last for at least 14 days (Jansen et al., 2009). Also, broccoli heads are flower heads and GLS profiles could be dramatically different between flowers and leaves (Smallegange et al., 2007). Alternatively, changes in other plant chemicals such as induced non-GLS secondary metabolites, or above- and belowground reallocation of primary metabolites may contribute to the observed herbivore responses to induced plants (Jansen et al., 2008; van Dam and Oomen, 2008; Poelman et al., 2010; Pierre et al., 2012). For instance, lower sugar levels were found in the leaves of root-induced plants, whereas both sugar and amino acid levels decreased in shoot-induced plants (van Dam and Oomen, 2008). Such plant responses resulted in differential effects on the performance of the generalist Ma. brassicae and the specialist P. rapae between root- and shoot-induced plants (van Dam and Oomen, 2008). Additional chemical analyses of flowers, leaves and roots at different time windows should be performed to link our results on colonization and performance of the different herbivores surveyed to modification of plant metabolites following induction.

Early season root induction by $D$. radicum larvae only slightly affected the aboveground community structure. The abundance of only one species, B. brassicae, was strongly modified on $D$. radicum infested plants. The increased colonization of the specialist aphid B. brassicae on root infested plants was already observed on wild mustard, Sinapis arvensis, infested with root feeding wireworms, Agriotes sp. larvae (Poveda et al., 2005). Previous field studies using a leaf herbivore to induce ozther brassicaceous species also resulted in increased colonization by the sap-sucking leaf specialist B. brassicae (Agrawal and Sherriffs, 2001; Poelman et al., 2010).

Taken together, our results show that root inductions by JA and SA have different consequences on the abundance of aboveground herbivores from root infestation by $D$. radicum, suggesting that these phytohormones are not appropriate elicitors to mimic root herbivory. Therefore, our results support growing evidence that other signals may be involved in the induction processes occurring belowground as already suggested by Erb et al. (2012).

\section{EFFECTS ON ROOT INDUCTION TREATMENTS ON THE QUALITY OF THE CROP}

Our study revealed that SA application did not induce any measurable costs, while JA only induced a diminution of plant heights

\section{REFERENCES}

Agrawal, A. A. (2000). Specificity of induced resistance in wild radish: causes and consequences for two specialist and two generalist caterpillars. Oikos 89, 493-500. doi: 10.1034/ j.1600-0706.2000.890308.x

Agrawal, A. A., and Sherriffs, M. F. (2001). Induced plant resistance and susceptibility to late-season herbivores of wild radish. Ann. Entomol. Soc. Am. 94, 71-75. doi: 10.1603/0013-8746 (2001)094[0071:IPRAST]2.0.CO;2

Bates, D., Maechler, M., and Bolker, B. (2011). lme4: linear mixed-effects but other parameters associated to plant quality were not affected. Similar effects on plant growth following JA application have been shown in other crop plants such as radish (Raphanus sativus cv. Comet) or maize (Zea mays L.) (Ueda and Kato, 1982; Shahzad et al., 2009). Previous infestation with D. radicum, on the other hand, resulted in lower visual quality. Considering the average weight of the broccoli heads harvested in our study, all the root inductions carried out resulted in yields sufficient to meet the commercial standards in conventional agriculture (Cerafel Brittany, 2007).

\section{CONCLUSION}

The present study documented important interactions between belowground induced defences and aboveground herbivore communities. Interestingly, these indirect effects mediated through the plant were found under field conditions despite uncontrolled heterogeneity in biotic and abiotic variables. Furthermore, the induced response effect on herbivore community dynamics followed some communal but also some substantially different patterns compared to the patterns usually observed after leaf induction. These results highlight the need to investigate both the effect of aboveground and belowground induced responses to better understand the mechanisms behind the structuring and functioning of insect herbivore communities in the field.

\section{ACKNOWLEDGMENTS}

The authors thank the staff of the "Domaine de la Motte" experimental station (INRA Center, Le Rheu, France), the staff of APBV (INRA, Center Le Rheu, France) and the following people for their excellent assistance with field experiment set up, surveys and harvest of broccoli plants: G. Nedelec, P. Leconte, C. Paillusson, A. Dechatre, S. Bouchebti, V. Chaminade, C. Paty, S. Dourlot, F. Kohandani-Tafresh, C. Josso, Y. Fournis, D. Poinsot, and D. Webb at Rennes University (France). The authors are also grateful to C. E. Raaijmakers at NIOO-KNAW (Netherlands) for glucosinolate analysis, Y. Outreman at INRA Center (Le Rheu, France) and D. Poinsot at Rennes University (France) for precious advice in statistics. This work was funded by a $\mathrm{PhD}$ grant from Région Bretagne to P. S. Pierre. models using S4 classes. R package version 0.999375-999342. Available online at: http://CRAN.Rproject.org/package $=$ lme4

Baur, R., Kostal, V., Patrian, B., and Stadler, E. (1996). Preference for plants damaged by conspecific larvae in ovipositing cabbage root flies: influence of stimuli from leaf surface and roots. Entomol. Exp. Appl. 81, 353-364. doi: 10.1046/j.15707458.1996.00106.x

Becker, G. J. M., and Spoel, S. H. (2006). Fine-tuning plant defence signaling: salicylate versus jasmonate. Plant Biol. 8, 1-10. doi: 10.1055/s-2005-872705
Bezemer, T. M., and van Dam, N. M. (2005). Above- belowground interactions via induced plant defenses. Trends Ecol. Evol. 20, 617-624. doi: 10.1016/ j.tree.2005.08.006

Bezemer, T. M., Wagenaar, R., van Dam, N. M., van Der Putten, W. H., and Wäckers, F. L. (2004). Aboveand below-ground terpenoid aldehyde induction in cotton, Gossypium herbaceum, following root and leaf injury. J. Chem. Ecol. 30, 53-67. doi: 10.1023/B:JOEC. $0000013182.50662 .2 \mathrm{a}$

Bezemer, T. M., Wagenaar, R., van Dam, N. M., and Wäckers, F.
L. (2003). Interactions between above- and belowground insect herbivores as mediated by the plant defense system. Oikos 101, 555-562. doi: 10.1034/j.16000706.2003.12424.x

Birch, A. N. E., Griffiths, D. W., Hopkins, R. J., MacFarlane Smith, W. H., and McKinlay, R. G. (1992). Glucosinolate responses of swede, kale, forage and oilseed rape to root damage by turnip root fly (Delia floralis) larvae. J. Sci. Food Agr. 60, 1-9. doi: 10.1002/jsfa.2740600102

Bligaard, J., Meadow, R., Nielsen, O., and Percy-Smith, A. (1999). 
Evaluation of felt traps to estimate egg numbers of cabbage root fly, Delia radicum, and turnip root fly, Delia floralis in commercial crops. Entomol. Exp. Appl. 90, 141-148. doi: 10.1046/j.1570-7458.1999.00432.x

Cerafel Brittany. (2007). Cahier des Charges Broccoli, Version 16.

Coaker, T. H., and Williams, D. A. (1963). The importance of some Carabidae and Staphylinidae as predators of the cabbage root fly, Eroioischa brassicae (Bouché). Entomol. Exp. Appl. 6, 156-164. doi: 10.1111/j.15707458.1963.tb00613.x

de Jong, R., and Städler, E. (1999). The influence of odour on the oviposition behaviour of the cabbage root fly. Chemoecology 9, 151-154. doi: 10.1007/s000490050047

Denno, R. F., Peterson, M. A., Gratton, C., Cheng, J., Langellotto, G. A., Huberty, A. F., et al. (2000). Feeding-induced changes in plant quality mediate interspecific competition between sap-feeding herbivores. Ecology 81, 1814-1827. doi: 10.1890/001 2-9658(2000)081[1814:FICIPQ]2.0. $\mathrm{CO} ; 2$

Ellner, S. P., McCauley, E., Kendall, B. E., Briggs, C. J., Hosseini, P. R., Wood, S. N., et al. (2001). Habitat structure and population persistence in an experimental community. Nature 412, 538-543. doi: $10.1038 / 35087580$

Englishloeb, G. M., Karban, R., and Hougeneitzman, D. (1993). Direct and indirect competition between spider-mites feeding on grapes. Ecol. Appl. 3, 699-707. doi: 10.2307/1942101

Erb, M., Flors, V., Karlen, D., De Lange, E., Planchamp, C., D'Alessandro, M., et al. (2009). Signal signature of aboveground induced resistance upon belowground herbivory in maize. Plant J. 59, 292-302.

Erb, M., Glauser, G., and Robert, C. (2012). Induced immunity against below ground insect herbivores activation of defenses in the absence of a jasmonate burst. J. Chem. Ecol. 38, 629-640. doi: 10.1007/s10886012-0107-9

Erb, M., Köllner, T., Degenhardt, J., Zwahlen, C., Hibbard, B., and Turlings, T. C. J. (2011a). The role of abscisic acid and water stress in root herbivore-induced leaf resistance. New Phytol. 189, 308-320. doi: 10.1111/j.1469-8137.2010.03450.x

Erb, M., Robert, C. A. M., Hibbard, B. E., and Turlings, T. C. J. (2011b). Sequential of arrival determines plant-mediated interactions between herbivores. J. Ecol. 99, 7-15. doi: 10.1111/j.1365-2745.2010.01757.x

Erb, M., Ton, J., Degenhardt, J., and Turlings, T. C. J. (2008). Interactions between arthropodinduced aboveground and belowground defenses in plants. Plant Physiol. 146, 867-874. doi: 10.1104/pp.107.112169

Ferry, A., Dugravot, S., Delattre, T., Christides, J.-P., Auger, J., Bagnères, A.-G., et al. (2007). Identification of a single widespread monomolecular odor differentially attractive to several Delia radicum ground dwelling predators in the field. J. Chem. Ecol. 33, 2064-2077. doi: 10.1007/s10886-007-9373-3

Finch, S., and Collier, R. H. (2000). Host-plant selection by insectsa theory based on 'appropriate/inappropriate landings' by pest insects of cruciferous plants. Entomol. Exp. Appl. 96, 91-102. doi: 10.1046/j.1570-7458. 2000.00684.x

Højsgaard, S., Halekoh, U. with contributions from Robison-Cox, J., Wright, K., and Leidi, A. (2011). doBy: doBy - Groupwise summary statistics, general linear contrasts, LSMEANS (leastsquares-means), and other utilities. R package version 4.4.3. Available online at: http://CRAN.Rproject.org/package $=$ doBy

Hopkins, R. J., Griffiths, D. W., Birch, A. N. E., and McKinlay, R. G. (1998). The influence of increasing herbivore pressure on the modification of glucosinolate content of swedes (Brassica napus ssp. rapifera). J. Chem. Ecol. 24, 2003-2019. doi: 10.1023/A:1020729524818

Hopkins, R. J., Griffiths, D. W., McKinlay, R. G., and Birch, A. N. E. (1999). The relationship between cabbage root fly (Delia radicum) larval feeding and the freeze-dried matter and sugar content of Brassica roots. Entomol. Exp. Appl. 92, 109-117. doi: 10.1046/j.1570-7458.1999.00530.x

Howe, G. A., and Jander, G. (2008). Plant immunity to insect herbivores. Ann. Rev. Plant Biol. 59, 41-66. doi: 10.1146/annurev. arplant.59.032607.092825

Huberty, A. F., and Denno, R. F. (2004). Plant water stress and its consequences for herbivorous insects: a new synthesis. Ecology 85, 1383-1398. doi: 10.1890/03-0352

Inbar, M., Doostdar, H., Leibee, G. L., and Mayer, R. T. (1999). The role of plant rapidly induced responses in asymmetric interspecific interactions among insect herbivores.
J. Chem. Ecol. 25, 1961-1979. doi: 10.1023/A:1020998219928

Jansen, J. J., Bro, R., Hoefsloot, H. C. J., van den Berg, F. W. J., Westerhuis, J. A., and Smilde, A. K. (2008). PARAFASCA: ASCA combined with PARAFAC for the analysis of metabolic fingerprinting data. J. Chemometr. 22, 114-121. doi: 10.1002/cem.1105

Jansen, J. J., van Dam, N. M., Hoefsloot, H. C. J., and Smilde, A. K. (2009). Crossfit analysis: a novel method to characterize the dynamics of induced plant responses. BMC Bioinformatics 10:425. doi: 10.1186/1471-2105-10-425

Kaplan, I., and Denno, R. F. (2007). Interspecific interactions in phytophagous insects revisited: a quantitative assessment of competition theory. Ecol. Lett. 10, 977-994. doi: 10.1111/ j.1461-0248.2007.01093.x

Karban, R., and Baldwin, I. T. (1997). Induced Responses to Herbivory. Chicago, IL: University of Chicago Press. doi: 10.7208/ chicago/9780226424972.001.0001

Kiddle, G. A., Doughty, K. J., and Wallsgrove, R. M. (1994). Salicylic acid-induced accumulation of glucosinolates in oilseed rape (Brassica napus L.) leaves. J. Exp. Bot. 45, 1343-1346. doi: 10.1093/jxb/45.9.1343

Kutyniok, M., and Muller, C. (2012). Crosstalk between above- and belowground herbivores is mediated by minute metabolic responses of the host Arabidopsis thaliana. J. Exp. Bot. 63, 6199-6210. doi: $10.1093 / \mathrm{jxb} / \mathrm{ers} 274$

Long, J. D., Hamilton, R. S., and Mitchell, J. L. (2007). Asymmetric competition via induced resistance: specialist herbivores indirectly suppress generalist preference and populations. Ecology 88, 1232-1240. doi: 10.1890/06-1585

Martinsen, G. D., Driebe, E. M. and Whitham, T. G. (1998). Indirect interactions mediated by changing plant chemistry: beaver browsing benefits beetles. Ecology 79, 192-200. doi: 10.1890/00129658(1998)079[0192:IIMBCP]2.0. $\mathrm{CO} ; 2$

Masters, C. J., Brown, V., and Kanganger, A. C. (1993). Plant mediated interactions between aboveground and belowground insect herbivores. Oikos 66, 148-151. doi: 10.2307/3545209

Mathur, V., Ganta, S., Raaijmakers, C. E., Reddy, A. S., Vet, L. E. M., and van Dam, N. M. (2011). Temporal dynamics of herbivore-induced responses in Brassica juncea and their effect on generalist and specialist herbivores. Entomol. Exp. Appl. 139, 215-225. doi: 10.1111/j.1570-7458.2011.01122.x

Moore, J. P., Paul, N. D., Whittaker, J. B., and Taylor, J. E. (2003). Exogenous jasmonic acid mimics herbivore-induced systemic increase in cell wall bound peroxidase activity and reduction in leaf expansion. Funct. Ecol. 17, 549-554. doi: 10.1046/j.1365-2435.2003.00767.x

Neveu, N., Grandgirard, J., Nenon, J. P., and Cortesero, A. M. (2002). Systemic release of herbivoreinduced plant volatiles by turnips infested by concealed rootfeeding larvae Delia radicum L. J. Chem. Ecol. 28, 1717-1732. doi: 10.1023/A:1020500915728

Neveu, N., Kacem, N., and Nenon, J. P. (1996). A method for rearing Trybliographa rapae, W. on Delia radicum, L. OILB/SROP Bull. 19, 173-178.

Orre, G. U. S., Wratten, S. D., Jonsson, M., and Hale, R. J. (2010). Effects of an herbivore-induc-ed plant volatile on arthropods from three trophic levels in brassicas. Biol. Control 53, 62-67. doi: 10.1016/j.biocontrol.2009.10.010

Pierre, P. S., Dugravot, S., Cortesero, A. M., Poinsot, D., Raaijmakers, C., Hassan, H. M., et al. (2012). Broccoli and turnip plants display contrasting responses to belowground induction by Delia radicum infestation and phytohormone applications. Phytochemistry 73, 42-50. doi: 10.1016/j.phytochem.2011.09.009

Pierre, P. S., Jansen, J. J., Hordijk, C. A., van Dam, N. M., Cortesero, A. M., and Dugravot, S. (2011). Differences in volatile profiles of turnip plants subjected to single and dual herbivory above- and belowground. J. Chem. Ecol. 37, 368-377. doi: 10.1007/s10886-011-9934-3

Poelman, E. H., Broekgaarden, C., van Loon, J. J. A., and Dicke, M. (2008). Early season herbivore differentially affects plant defense responses to subsequently colonizing herbivores and their abundance in the field. Mol. Ecol. 17, 3352-3365. doi: 10.1111/j.1365294X.2008.03838.x

Poelman, E. H., van Loon, J. J. A., van Dam, N. M., Vet, L. E. M., and Dicke, M. (2010). Herbivoreinduced plant responses in Brassica oleracea prevail over effects of constitutive resistance and result in enhanced herbivore attack. Ecol. Entomol. 35, 240-247. doi: 10.1111/j.1365-2311.2010.01179.x 
Poveda, K., Steffan-Dewenter, I., Scheu, S., and Tscharntke, T. (2005). Effects of decomposers and herbivores on plant performance and aboveground plant-insect interactions. Oikos 108, 503-510. doi: 10.1111/j.0030-1299. 2005.13664.x

Qiu, B.-L., Harvey, J. A., Raaijmakers, C. E., Vet, L. E. M., and van Dam, N. M. (2009). Nonlinear effects of plant root and shoot jasmonic acid application on the performance of Pieris brassicae and its parasitoid Cotesia glomerata. Funct. Ecol. 23, 496-505. doi: 10.1111/j.13652435.2008.01516.x

R Core Team. (2011). R: A Language and Environment for Statistical Computing. $R$ Foundation for Statistical Computing. Vienna. Available online at: http://www. R-project.org/

Redman, A. M., Cipollini, D. F. Jr., and Schultz, J. C. (2001). Fitness costs of jasmonic acid-induced defense in tomato, Lycopersicon esculentum. Oecologia 126, 380-385. doi: 10.1007/s004420000522

Robert, C. A. M., Erb, M., Hibbard, B. E., French, B. W., Zwahlen, C., and Turlings, T. C. J. (2012). A specialist root herbivore reduces plant resistance and uses an induced plant volatile to aggregate in a density-dependent manner. Funct. Ecol. 26, 1429-1440. doi: 10.1111/j.1365-2435.2012.02030.x

Shahzad, A. N., Pollmann, S., and Schubert, S. (2009). "Does jasmonic acid control the maize shoot growth during the first phase of salt stress?" in The Proceedings of the International Plant Nutrition Colloquium XVI. (Davis, CA: Department of Plant Sciences, UC)
Shiojiri, K., Takabayashi, J., Yano, S., and Takafuji, A. (2002). Oviposition preferences of herbivores are affected by tritrophic interaction webs. Ecol. Lett. 5, 186-192. doi: 10.1046/j.1461-0248. 2002.00292.x

Smallegange, R. C., van Loon, J. J., Blatt, S. E., Harvey, J. A., Agerbirk, N., and Dicke, M. (2007). Flower vs. leaf feeding by Pieris brassicae: glucosinolate-rich flower tissues are preferred and sustain higher growth rate. J. Chem. Ecol. 33, 1831-1844. doi: 10.1007/s10886-007-9350-x

Soler, R., Bezemer, T. M., van der Putten, W. H., Vet, L. E. M., and Harvey, J. A. (2005). Root herbivore effects on aboveground herbivore, parasitoid and hyperparasitoid performance via changes in plant quality. J. Anim. Ecol. 74, 1121-1130. doi: 10.1111/j.13652656.2005.01006.x

Soler, R., Harvey, J. A., Kamp, A. F. D., Vet, L. E. M., van der Putten, W. H., van Dam, N. M., et al. (2007). Root herbivores influence the behaviour of an aboveground parasitoid through changes in plant-volatile signals. Oikos 116, 367-376. doi: 10.1111/j.0030-1299. 2007.15501.x

Thaler, J. S. (1999). Induced resistance in agricultural crops: effects of jasmonic acid on herbivory and yield in tomato plants. Environ. Entomol. 28, 30-37.

Ueda, J., and Kato, J. (1982). Inhibition of cytokinin-induced plant growth by jasmonic acid and its methyl ester. Physiol. Plantarum 54, 249-252. doi: 10.1111/j.13993054.1982.tb00255.x

van Dam, N. M., and Baldwin, I. T. (2001). Competition mediates costs of jasmonate-induced defences, nitrogen acquisition and transgenerational plasticity in Nicotiana attenuata. Funct. Ecol. 15, 406-415. doi 10.1046/j.1365-2435.2001.00533.x van Dam, N. M., and Heil, M. (2011). Multitrophic interactions below and above ground: en route to the next level. J. Ecol. 99, 77-88. doi: 10.1111/j.1365-2745.2010.01761.x

van Dam, N. M., and Oomen, M. W. A. T. (2008). Root and shoot jasmonic acid applications differentially affect leaf chemistry and herbivore growth. Plant Signal. Behav. 3, 91-98. doi: 10.4161/psb.3.2.5220

van Dam, N. M., and Raaijmakers, C. E. (2006). Local and systemic induced responses to cabbage root fly larvae (Delia radicum) in Brassica nigra and B. oleracea. Chemoecology 16, 17-24. doi: 10.1007/s00049-0050323-7

van Dam, N. M., Raaijmakers, C. E., and van der Putten, W. H. (2005). Root herbivory reduces growth and survival of the shoot feeding specialist Pieris rapae on Brassica nigra. Entomol. Exp. Appl. 115, 161-170.

van Dam, N. M., Witjes, L., and Svatoš, A. (2004). Interactions between aboveground and belowground induction of glucosinolates in two wild Brassica species. New Phytol. 161, 801-810. doi: 10.1111/j.1469-8137.2004.00984.x

van Poecke, R. M. P., and Dicke, M. (2002). Induced parasitoid attraction by Arabidopsis thaliana: involvement of the octadecanoid and the salicylic acid pathway. J. Exp. Bot. 53, 1793-1799. doi: 10.1093/jxb/erf022

van Zandt, P. A., and Agrawal, A. A. (2004). Community-wide impacts of herbivore-induced plant responses in milkweed (Asclepias syriaca). Ecology 85, 2616-2629. doi: 10.1890/03-0622

Viswanathan, D. V., Narwani, A. J. T., and Thaler, J. S. (2005). Specificity in induced plant responses shapes patterns of herbivore occurrence on Solanum dulcamara. Ecology 86, 886-896. doi: 10.1890/04-0313

Conflict of Interest Statement: The authors declare that the research was conducted in the absence of any commercial or financial relationships that could be construed as a potential conflict of interest.

Received: 17 May 2013; accepted: 22 July 2013; published online: 21 August 2013. Citation: Pierre SP, Dugravot S, Hervé $M R$, Hassan HM, van Dam NM and Cortesero AM (2013) Belowground induction by Delia radicum or phytohormones affect aboveground herbivore communities on field-grown broccoli. Front. Plant Sci. 4:305. doi: 10.3389/fpls. 2013.00305

This article was submitted to PlantMicrobe Interaction, a section of the journal Frontiers in Plant Science.

Copyright (c) 2013 Pierre, Dugravot, Hervé, Hassan, van Dam and Cortesero. This is an open-access article distributed under the terms of the Creative Commons Attribution License (CC BY). The use, distribution or reproduction in other forums is permitted, provided the original author(s) or licensor are credited and that the original publication in this journal is cited, in accordance with accepted academic practice. No use, distribution or reproduction is permitted which does not comply with these terms. 